\title{
Religion and social values for sustainability
}

\author{
Christopher D. Ives ${ }^{1}\left[\right.$ ] Jeremy Kidwell ${ }^{2}$
}

Received: 3 August 2018 / Accepted: 11 January 2019 / Published online: 19 February 2019

(c) The Author(s) 2019

\begin{abstract}
Discourse on social values as they relate to environmental and sustainability issues has almost exclusively been conducted in a secular intellectual context. However, with a renewed emphasis on culture as defining and shaping links between people and nature, there has been an increasing level of scholarly attention to the role of religion and spirituality in defining and understanding social values. In this article we explore the intersection of religion and social values for sustainability. First, we consider this nexus as it has been explored in existing scholarship. We acknowledge a body of research that has suggested that many religions are broadly associated with self-transcendent values. However, the degree to which they are translated into pro-environmental attitudes and behaviour varies according to context. Second, we argue that while there is much potential support for human values for sustainability within religious traditions, it is essential that religion is seen as a complex, multi-scalar and multi-dimensional institutional phenomena. Consequently, analysis of the relationship between religion and social values must account for the context of narratives, histories and practices. Third, using this lens, we show how religious perspectives can contribute to operationalising theories of systemic change for sustainability. Finally, we outline key principles for further sustainability research seeking to advance knowledge on the relationship between religion and social values.
\end{abstract}

Keywords Religion $\cdot$ Values $\cdot$ Narratives $\cdot$ Practices $\cdot$ Worldviews $\cdot$ Sustainability transformation

\section{Theorising religion and social values}

Religion is one of the most prominent and wide-reaching social institutions, touching and shaping virtually every sphere of culture and society. According to the Pew Research Centre, approximately $84 \%$ of the world's population are affiliated with a religion (Pew Research Centre 2017). Given this ubiquity and social influence of religion we argue that commentary on social values and sustainability ought to consider the place of religion carefully. There is a diversity in practices and worldviews across (and even within) different

Handled by: Carena van Riper, University of Illinois at UrbanaChampaign, United States.

Christopher D. Ives

chris.ives@nottingham.ac.uk

1 School of Geography, University of Nottingham, University Park, Nottingham NG7 2RD, UK

2 Department of Theology and Religion, University of Birmingham, Birmingham, UK religious traditions. This makes identifying a clear definition of religion difficult. We affirm the approach by HaluzaDeLay (2014) who defined religion broadly as including "beliefs, worldviews, practices, and institutions that cross borders, time and scale from the level of individuals all the way to transnational and transhistorical movements" ( $p$. 261). He noted also that the western notion of equating religion with an established set of beliefs does not represent many eastern or traditional religious systems, which often emphasise collective practices as much as cognitive beliefs and may lack firmly established institutionalised teachings. In this article, we will adopt this broad definition of religion, stressing both belief systems and institutional structures and dynamics.

There is a voluminous literature on human values, which has amassed over many decades. Anthropologists have adopted a grounded and embedded approach to studying values, based on the assumption that individual communities birth and express values in unique ways, precluding meaningful conclusions about value universality. In stark contrast, early work on values grounded in psychology sought 
to unearth universal structures of human values which can enable comparisons across cultures and contexts (Schwartz 1992). Values have also been identified as deeply held antecedents to environmental behaviours (Stern 2000; Steg and Vlek 2009). Alongside this, human values at different scales and levels of aggregation have increasingly become a topic of research in the context of environmental management and sustainability science (Ives and Kendal 2014; Kenter et al. 2015; Tadaki et al. 2017), with much of this literature concerned with values for ecosystems and human-nature relationships (e.g., Chan et al. 2016; Cooper et al. 2016). While the relevance of diverse cultural resources is acknowledged in this scholarship, there is little explicit recognition of the more specific role of religion in establishing and shaping social values in society. In this article we refer to social values as a broad term which encompasses human values held or expressed at different scales of aggregation (sensu Ives and Kendal 2014), although we acknowledge that some scholars have been careful to distinguish between different value dimensions such as shared, social and cultural values (Kenter et al. 2015).

The concept of social values is gaining increasing attention within sustainability science. A number of commentators have called for social values to be influenced or shifted to drive change necessary for a sustainable future (Schultz and Zelezny 2003). Indeed, Martin et al. (2016) argued that "we need fundamental shifts in values that ensure transition from a growth-centered society to one acknowledging biophysical limits and centered on human well-being and biodiversity conservation" (p. 6105). Some scholars have questioned the use or veracity of policy interventions to precipitate transitions in social values (Manfredo et al. 2017), opening up a debate on the subject (Ives and Fischer 2017). To progress this line of enquiry, Kendal and Raymond (2019) present a conceptual framework for how values for sustainability may shift within society. In this context, we contend that any discussion of value shift should consider the role of religion given its influence on values and worldviews that are relevant to environmental sustainability (Rolston 2006).

Our overarching argument here is about inclusivity in values studies, particularly that more effort should be made to engage with religion for both pragmatic reasons, e.g., because such an engagement might enhance the existing panoply of approaches to social and environmental values, and also for holistic reasons, e.g., existing engagements with persons or communities on the level of values cannot exclude such a ubiquitous socio-cultural feature. Given this inclusive approach, it is sensible to work with a broad definition of religion so as to enable a maximally inclusive analytical frame. However, there is an important caveat to be made at the outset. Though, as we will note below, some studies indicate broadly positive trends on environmental values across different religions, in practice, engagements with religion as a vector for values studies will likely be most effective when they are conducted within particularised contexts, i.e., either with a specific religious tradition (say, German Lutheran Christianity or Nyingma Buddhism) or at a specific scale (i.e., with grassroots practitioners, clergy, or elites). The identification of generic symmetries across religious value systems can obscure quite important differences, the knowledge of which may be crucial for effective practitioner engagement by policy-makers on the level of values. In this paper, we are working broadly within the scholarly field of religious studies, but will attempt to substantiate our claims with more specific reference to Christianity. The reasons for this are pragmatic, as a study of this length simply cannot account for all major world religions and their sects, and superficial engagement can veer towards tokenism which we prefer to avoid. In this way, our paper explores how religion intersects theoretically and practically with scholarship on social values before considering the complex contextual and scalar dynamics that complicate such a discourse. We position this article with a focus on sustainability and so progress to explore what role religion has in pursuing transformations for sustainability. Finally, we consider how taking seriously this place of religion may affect future research and application of social values theory.

\section{Scholarship on religion and social values}

The term 'value' can connote a range of different meanings and interpretations. Values can equally refer to broad underlying principles in life, important features within a landscape, or monetary figures assigned to goods or services. Tadaki et al. (2017) helpfully outlined a broad typology of value concepts in an environmental context. In exploring the intersection of religion with social values, we focus our inquiry on transcendental or 'held' values. Most commonly, these values are associated with the work by Shalom Schwartz on 'universal' human values (Schwartz 1992, 1994). Kluckhohn and Strodbeck (1961) first theorised that universal values might be arranged along various continua, and this was refined by a range of scholars, most prominently by Schwartz. Most important were two continua: (1) from self-transcendence (e.g., protecting the environment) to selfenhancement (e.g., social power), and (2) from openness to change (e.g., freedom) to tradition (e.g., self-discipline). Scholars have found strongest support for pro-environmental behaviour and attitudes within the self-transcendence dimension of human values (de Groot and Steg 2007).

How then does religion intersect with these values? The first study in English to explore the correlation of religion with specifically environmental attitudes was conducted by Hand and Van Liere (1984), who developed a simple 
and now highly used instrument (cf. Hawcroft and Milfont 2010), the "New Environmental Paradigm" to test for environmental value orientations. In their initial 1976 survey of Washington State, USA residents $(n=806)$, they found that respondents with affiliations to institutional religion (e.g., tradition-oriented) were more likely to have a mastery-overnature value orientation (e.g., self-enhancement). However, subsequent work, such as the more broadly construed study by Schwartz and Huismans (1995) found that religiosity of adherents to Orthodox, Catholic, Protestant and Jewish faiths correlated positively with benevolence, tradition, conformity and security values, and negatively with power, achievement, hedonism, stimulation, and self-direction. Subsequent research has been mixed, but a number of studies have confirmed Schwartz and Huismans' patterns across many different cultures and faiths. A meta-analysis conducted in 2004 showed that religious people rated highly on values that promote conservation of social and individual order along with limited self-transcendence (i.e., benevolence but not universalism) (Saroglou et al. 2004). More recently, in their cross cultural study of six different types of faith, Hyland et al. (2010) explored whether a sense of 'special connection' to people, nature, places and the universe is present in different traditions. They found that this 'special connection' was indeed correlated with self-perceived spirituality, and was associated with self-transcendence values.

With religiosity shown to be negatively associated with self-enhancement values such as hedonism, achievement and power, one might be tempted to think that religion is a predictable motivator for environmental sustainability. While this may hold in the cases we have highlighted above, in practice the relationship between religiosity and environmental attitudes and behaviours is complex and correlations between religious identity and pro-environmental values can be weak. Indeed, some scholars argue that the mediating effect of political ideology and economic status is a far stronger predictor than religiosity per se, and this varies enormously across cultures (Ester and Seuren 1992). Religious communities can also serve as the site for quite profound disagreements over values, and contemporary study in the field of religion has indicated that differences in values may exist even between individuals within the same religious community (Woodhead et al. 2016). Our point here is not to suggest that all religions are fundamentally the same, or that they can be distilled to a common set of values. Conversely, however, the presence of diversity and unique cases, does not preclude the relevance of religion to values research. If anything, this commends further, more granular research, so that generalisations may be contextualised adequately. The state of research in this area remains nascent and underdeveloped, and this is even more acutely the case with regards to Eastern religions (c.f. Gifford and Nilsson 2014). Similarly, religions may not always function as an ideal or predictable policy lever for change. Indeed, Narayanan (2001) cautions against overstating religious values as influencing behaviour. However,-emphasising the pragmatic dimension of our argument highlighted abovethese symmetries seem to commend religion as an important sphere for further engagement on the level of values. Religion is far too ubiquitous a socio-cultural phenomenon to ignore.

\section{Religion and social values: a complicated relationship}

As we have already hinted above, while religion certainly can be viewed as a fertile source of values that align with sustainability, simply equating religion with certain sets of values does not adequately capture the more complex interplay of religious belief, belonging, and environmental values. Any serious consideration of the intersection between religion and values for sustainability must not simply force religion into existing value frameworks, despite the empirical relationships described in the previous section.

One of the dominant discourses that has considered human values is within the field of social psychology. Although social psychology has amassed detailed knowledge of the structure and composition of values in societies around the world, few scholars of social values have explored why certain values emerge in different contexts. Recently, some social psychologists have emphasised the systems view of values, namely that values are not simply static constructs in people's minds, but are deeply embedded in culture and ecology (Kitayama 2002; Manfredo et al. 2014). We also adopt this perspective, but suggest that values are in part an expression of dominant narratives within cultures, with held narratives providing a locally inflected mesh in which values carry their meaning. Taking the broad view of religion that we outlined above, even 'secular' narratives (e.g., the American dream, the quest for economic growth) can been seen to have some religious or quasi-religious dimensions. Moreover, in reality, there is a melding of myriad narratives within most societies. These narratives may be considered as forming part of a larger 'worldview' out of which individuals operate. According to research by Hedlund-de Witt (2012) and Hedlund-de Witt et al. (2014), worldviews are comprised of inter alia axiology (core values), as well as ontology (including a cosmogony), anthropology (the purpose of the human being) and societal vision (how society should be organised or function). Understanding values (axiology) apart from these other dimensions is, therefore, a superficial reading of society.

Another key factor which must be considered in seeking to understand the role of religious values in sustainability is the way that religious identity and belonging works at 
multiple scales, from individuals to groups to international bodies and values across these scales do not always align. Scale has been extensively studied within environment and sustainability fields. For example, Van Riper et al. (2017) described how external factors (e.g., institutions, social structures) and internal processes (e.g., attitudes, emotions) relate to one another to inform how people benefit from nature. Such relationships across scales were explored empirically by Van Riper et al. (2019) where significant associations were found between cultural and individual values among visitors to nature reserves in Alaska. In the same way, understanding religion's relationship to values for sustainability requires assessment of relationships among different scales. For ease of explanation, we conceptualise religious values as present across three scales: the individual scale, the community scale, and the formal institutional scale. These three levels interact with one another and are permeable to the (often notionally secular) socio-cultural and ecological context within which they are embedded (see Fig. 1). The formal institutional scale includes public statements by major religions or denominations. For example, the Buddhism Faith Statement on Ecology (Fossey 2003), the World Council of Churches "Justice, Peace and Creation Concerns" (World Council of Churches 1983) or the Bristol Faith Commitments compiled by the Alliance of Religions and Conservation (The Alliance of Religions and Conservation 2015). The community scale would represent

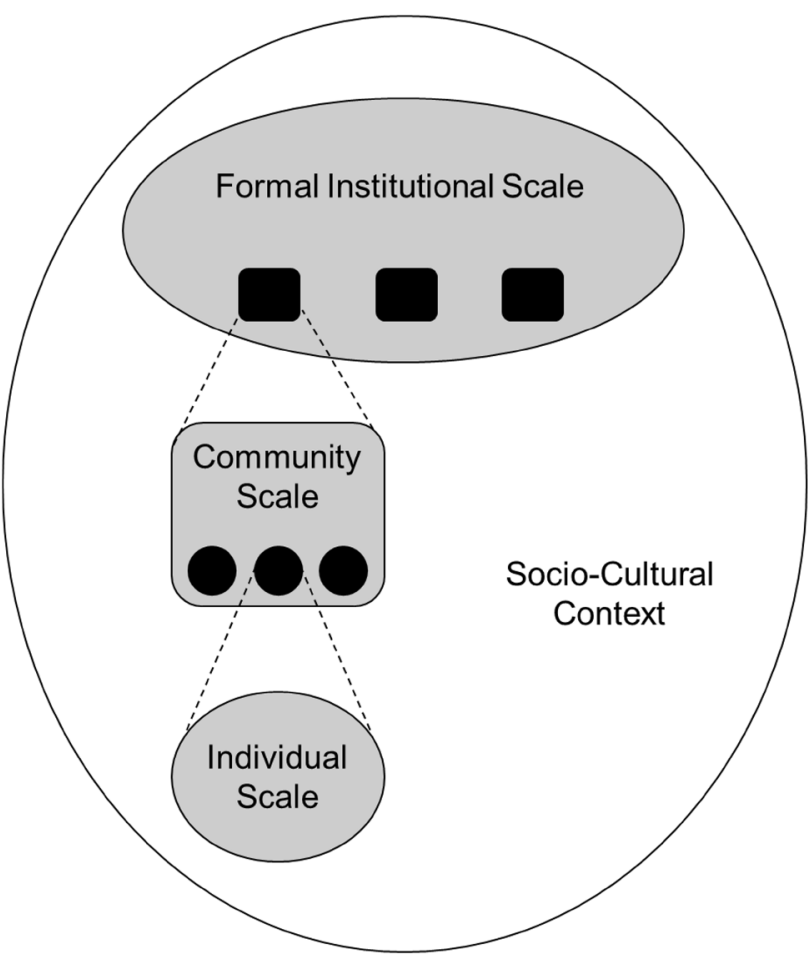

Fig. 1 Schematic diagram of the scales at which religious values for sustainability can be held and expressed the teachings and viewpoints of particular churches, temples or faith communities. The individual scale is the values held by individual members of these communities, which may be highly diverse and conflict at times with the values espoused at the other scales.

To demonstrate the complex dynamics across these scales, we take as one recent example the Roman Catholic encyclical by Pope Francis, Laudato Sí (which is examined in depth by Christie et al. 2019). The publication of encyclicals are major events, occurring infrequently, and carrying particular normative force as formal religious teaching by the leader of the Roman Catholic church. Laudato Sí (24 May 2015), the first encyclical on the environment, was widely hailed as precipitating a change towards (or intensification of) pro-environmental values among Roman Catholics, who number nearly a billion worldwide. Interviews conducted by Kidwell (unpublished data), indicated that there was indeed a boost perceived by elite actors (priests and denominational leaders). However, a study by the Associated Press-NORC Center for Public Affairs Research and researchers at Yale University indicated that in spite of public attention, only $40 \%$ of American Catholics "are aware of Pope Francis's efforts to emphasize global warming as a priority issue for the Catholic Church" and attitudes towards climate change were shown to be virtually unchanged (The Associated Press-NORC Center for Public Affairs Research 2015). Again, our point here is not that values are uninfluenced, but that the dissemination and mobilisation of values is complex (Kidwell et al. 2018). Popular views often hold that the Roman Catholic church is hierarchical and top-down. However, in practice, this research suggests that within the American Roman Catholic context, values are often consolidated in free-standing ways at different scales: from individual, to parish, to diocese, to regional ecumenical partnerships, to global community. As Li et al. (2016) suggest, at each of these levels, actors may be subject to different cross-pressuring effects, whereby political and religious affiliations are in conflict around an issue like climate change. The point we want to make is that these scales are related in a complex way, with values being consolidated and then negotiated across scales. In another qualitative study of religious environmental organisations, Ellingson et al. (2012) ascertained that religious environmental movement organisations (REMOs) were more likely to collaborate and build alliances with other groups that shared their religious affiliation or theological frame. These researchers also concluded that a "REMOs' religious culture shapes the structure of the movement field, which in turn may limit the scope and efficacy of religious environmentalism" (Ellingson et al. 2012 p. 269).

While we have noted ways that religion is pluriform and its relation to sustainability possibly ambiguous, it is important to appreciate the ways that the concept of 
"sustainability" may itself also be unstable (Johnston 2013). It is impossible to locate a universally agreed upon definition of sustainability and as such scholars and practitioners have developed definitions to fit specific purposes (White 2013). In this ambiguous context, we may appreciate a range of ways that religion doesn't always sit comfortably with 'sustainability' as a concept. Not only may religious communities emphasise particular dimensions of sustainability-emphasising human health over ecological integrity for instance-religious perspectives may also challenge sustainability as a normative goal. The concept of the "common good" discussed by Christie et al. (2019) within Catholic teaching as an alternative (albeit not inconsistent) aspirational goal to sustainability is a good example. Appreciating narratives and worldviews of faith communities relevant to conservation activities has recently been emphasised as best-practice within the Society for Conservation Biology (Schaefer and Higgins 2017). The Christian worldview, for example, encompasses a future 'hope' and the possibility of the transformation of terrestrial life. This in turn may underwrite some level of indifference towards landscape transformation. But is a static ecosystem desirable? Under some definitions of "sustainability" environmental scientists might assume that preservation of 'status quo' is the objective, but as some restoration ecologists have argued more recently, disruption and novelty may be a necessary component of healthy environmental systems. Thus, effective practice for sustainability goes beyond aligning messaging and action with values.

While on one hand, reductive or distilled accounts of universal values within religion may be useful in schematising their relation to the environmental subset of universal values, there are other ways in which religion can challenge such attempts. Although values are shaped by culture and context at multiple scales, they can take on a diverse array of ultimately personal expressions. As described earlier, religion encompasses a wide array of components: traditions, beliefs, practices and institutions, and these components may be used in different ways. Many societies oppose the notion of 'religion' and hold instead that spiritual beliefs and practices are simply expressions of their worldview. Values can be embedded, shaped and reinforced through socialisation as faith communities of individuals participate in practices and form identities and relational bonds (e.g., Kidwell et al. 2018). Religious communities may, therefore, be prime examples of contexts where social practice based understandings of behaviour (Shove 2010) intersect with value-driven theory (e.g., Ajzen 1991; Stern 2000). The importance of practices in religious contexts must not be downplayed, for, as Reckwitz (2002) highlighted, practices 'carry' their subjects and subjects 'carry' their practices. Yet, there is likely to be a mutual reinforcing of behaviours and values (particularly when such behaviours include contemplation of scripture and teaching). In this way, religion is a powerful contextual and institutional influence on social values for sustainability.

\section{Religion for sustainability science}

As an institution, religion combines beliefs, practices and structures, and influences a very large proportion of the global population. As such it has enormous potential to effect change for sustainability. In this section of the article, we will relate to recent conceptual frameworks within sustainability science to consider the role of religion in shaping values for sustainability.

There is an emphasis on systems analysis in sustainability science which has been motivated by the awareness that wholesale systemic transformation is necessary to address the imminent threat of runaway climate change and ecological collapse. Meadows (1999) introduced the notion of 'leverage points' within systems where interventions can be targeted to bring about change. In the context of sustainability, shallow leverage points consist of parameters (such as taxes, subsidies, etc.) and feedbacks (i.e., interactions between system elements) (Abson et al. 2017). These have tended to be the focus of sustainability policies to date. In contrast, deep leverage points are those that are more difficult to influence, but would amount to more substantial change in a system. These include the design of the system (the social structures and institutions), and 'intent' of the system (underlying values, goals and worldviews of actors) (Abson et al. 2017). A similar heuristic has been proposed by O'Brien (2018) whereby sustainability interventions are conceptualised as occurring within three 'spheres of transformation', namely the personal, political and practical spheres. The practical sphere is akin to shallow leverage points, while the personal sphere is the deepest locus of change and includes beliefs, values, worldviews and paradigms.

Koehrsen $(2015,2017)$ explores how religion might theoretically function as an agent of change/transitions. Situating his research within the literature on multi-level perspectives on socio-technical systems (Geels 2002; Geels and Schot 2007), he argues that religion has potential to undergo change both internally (e.g., through promoting eco-theology or adopting 'green' practical interventions) as well as within broader society (e.g., disseminating pro-environmental values). This needs more consideration, particularly regarding value shift from the inside of organisations as well as value dissemination. We hold that religion does indeed have great capacity to effect change within society because its activities span both deep and shallow leverage points. Recent work by Bomberg and Hague (2018) highlights the 
possible role of religion as a cultural "resource" that might be leveraged for social adaptation in the midst of societies responding to environmental change, or towards attempts to mobilise mitigation efforts on a broader level. We concur, therefore, with Koehrsen (2017) that greater research is necessary on how such transformation can take place.

How might religion shape social values for sustainability? We agree with Everard et al. (2016) that "society progresses not (generally) through top-down leadership, but instead through progressive formalisation of values expressed, shared and moderated, then consolidated by societal processes." Religion is one such key process that can enable the emergence and dissemination of values across multiple social scales.

\section{Key considerations for integrating religion with social values scholarship}

\section{Post-secular identity}

In the latter half of the twentieth century, a range of sociologists of religion declared the formal decline of religion in many Western nations. One of the classic examples of this is the declaration by Peter Berger in 1968, "By the twenty-first century, religious believers are likely to be found only in small sects, huddled together to resist a worldwide secular culture." (Berger 1968). However, at the turn of the millennium, attitudes shifted based on reckoning with empirical data. In a way that was inconceivable decades earlier, Berger reversed his position at the turn of the millennium: "far from being in decline in the modern world, religion is actually experiencing a resurgence ... the assumption we live in a secularized world is false. ... The world today is as furiously religious as it ever was" (Berger 1999, p. 2). In this new post-secular condition, there has been a dramatic resurgence of both new and old religions across the Global South and also within Western societies there has been a resurgence. In the latter case, however, this resurgence has been far more implicit (as we have already observed above regarding the varying forms religion may take). Though new theories of the post-secular West have been circulating (Grace Davies, Jose Casanova, Charles Taylor), social analysis outside sociology has been slow to adjust to this new diagnosis, and environmental policy is no exception. Conservation practitioners working in Global South contexts are now advised to be careful (cf. Society for Ecological Restoration principles) to engage with religious values to ensure resilient projects and integration with local populations. Yet in Western contexts, conservation work can often be designed and executed in ways that remain secular, with little attention to local religious commitments and belongings. This mismatch is a problem in terms of inconsistent practice, and also represents a loss for work on environmental transitions within Western European contexts, as we will suggest further below.

\section{Universal versus local}

As we have noted above, across the wide variety of global religious traditions, some empirical studies have identified value symmetries which transcend individual differences across different traditions (Saroglou et al. 2004). However, these symmetries often appear most fully within homogenous societies. Furthermore, the way that values are expressed remains inflected by local cultural norms and practices. This means that while we may theorise consistency on the matter of self-transcendence, the actual ways that this may be expressed can vary quite dramatically across different contexts and even within more pluralistic societies. Attention to geo-political-cultural context and the possible differences in value expression is essential, and religion is a key way to track some of these matters of local value inflection.

In contrast to value symmetry across different religions, there can also be profound divergence in attitudes and practice within a single religious tradition. A clear example of this is Christian belief within the US context. While certain values are held in common across US society such as self-actualisation and liberty, conservative Christian evangelical groups have clashed dramatically with liberal Christians in relation to issues such climate change (Jones et al. 2014). There is a need for research to delve beneath the superficial rhetoric presented from both sides, to uncover whether these attitudinal clashes are the result of fundamental value differences or whether they are rooted in differing expressions of similar value sets.

\section{Instrumentalisation of religion}

As the potential for religion to be a powerful vehicle for progressing sustainability is increasingly realised (Hitzhusen and Tucker 2013), there is a risk that scholars and practitioners will view religious communities (and religion more generally) as merely instrumental to furthering a normative sustainability agenda. As we have already mentioned, it is essential that sustainability scholars begin first with understanding the complexities of religious contexts (including narratives, histories, practices) rather than simply analysing religion through the lens of academic value theory. We suggest that deliberative methods of value elicitation (Kenter et al. 2014) may be useful in seeking to bring together sustainability scholars and 
people of faith. Such methods can help to find common ground and reveal authentically where conflict and alignment lies between religion and values that are compatible with sustainability outcomes.

\section{Conclusion}

We have explored in this article the complex relationship between religion and social values for sustainability. While there are consistent trends regarding values promoted by major faith traditions and certain values operationalised within universal human values theory, religion comprises far more than the promotion of particular values. To progress research on the intersection of human values and religion, we suggest that religion must be understood as a multi-faceted embodied institution of substantial social and political relevance. This broad understanding of religion thus enables scholarship on social values for sustainability to connect with theories of social transformation. We encourage scholars pursuing such a research agenda to recognise that values are not freestanding but are connected to social practices and institutional dynamics, to pay attention to local expressions of values embedded in religious contexts, and to embrace more embedded vernacular than that of social psychological theory (e.g., concepts such as compassion/love rather than self-transcendence).

Open Access This article is distributed under the terms of the Creative Commons Attribution 4.0 International License (http://creativeco mmons.org/licenses/by/4.0/), which permits unrestricted use, distribution, and reproduction in any medium, provided you give appropriate credit to the original author(s) and the source, provide a link to the Creative Commons license, and indicate if changes were made.

\section{References}

Abson DJ, Fischer J, Leventon J et al (2017) Leverage points for sustainability transformation. Ambio. https://doi.org/10.1007/ s13280-016-0800-y

Ajzen I (1991) The theory of planned behavior. Organ Behav Hum Decis Process 50:179-211

Berger P (1968) A bleak outlook is seen for religion. New York Times, February 25, p 3

Berger P (ed) (1999) The desecularization of the world: a global overview. In: The desecularization of the world: resurgent religion and world politics. William B. Eerdmans Publishing Company, Grand Rapids, pp 1-18

Bomberg E, Hague A (2018) Faith-based climate action in Christian congregations: mobilisation and spiritual resources. Local Environ 23:582-596. https://doi.org/10.1080/13549839.2018.14498 22

Chan KMA, Balvanera P, Benessaiah K et al (2016) Why protect nature? Rethinking values and the environment. Proc Natl Acad Sci 113:1462-1465. https://doi.org/10.1073/pnas.1525002113
Christie I, Gunton R, Hejnowicz AP (2019) Sustainability and the common good: Catholic social teaching and 'integral ecology' as contributions to a framework of social values for sustainability transitions. Sustain Sci

Cooper N, Brady E, Bryce R, Steen H (2016) Aesthetic and spiritual values of ecosystems: recognising the ontological and axiological plurality of cultural ecosystem "services". Ecosyst Serv 21:218-229. https://doi.org/10.1016/j.ecoser.2016.07.014

de Groot JIM, Steg L (2007) Value orientations to explain beliefs related to environmental significant behavior: how to measure egoistic, altruistic, and biospheric value orientations. Environ Behav 40:330-354

Ellingson S, Woodley VA, Paik A et al (2012) The structure of religious environmentalism: movement organizations, interorganizational networks, and collective action. J Sci Study Relig 51:266-285

Ester P, Seuren B (1992) Religious beliefs and environmental attitudes: an empirical test of the Lynn White hypothesis in fourteen nations. Soc Wetenschap 35:20-39

Everard M, Reed MS, Kenter JO (2016) The ripple effect: Institutionalising pro-environmental values to shift societal norms and behaviours. Ecosyst Serv. https://doi.org/10.1016/j.ecoser.2016.08.001

Fossey K (2003) Buddhist faith statement. In: Alliance of religions and conservation. http://www.arcworld.org/faiths.asp?pageID=66. Accessed 3 Aug 2018

Geels FW (2002) Technological transitions as evolutionary reconfiguration processes: a multi-level perspective and a casestudy. Res Policy 31:1257-1274. https://doi.org/10.1016/S0048 $-7333(02) 00062-8$

Geels FW, Schot J (2007) Typology of sociotechnical transition pathways. Res Policy 36:399-417. https://doi.org/10.1016/j.respo 1.2007.01.003

Gifford R, Nilsson A (2014) Personal and social factors that influence pro-environmental concern and behaviour: a review. Int J Psychol 49:141-157

Haluza-Delay R (2014) Religion and climate change: varieties in viewpoints and practices. Wiley Interdiscip Rev Clim Change 5:261-279. https://doi.org/10.1002/wcc. 268

Hand CM, Van Liere KD (1984) Religion, mastery-over-nature, and environmental concern. Soc Forces 63:555-570

Hawcroft LJ, Milfont TL (2010) The use (and abuse) of the new environmental paradigm scale over the last 30 years: a meta-analysis. J Environ Psychol 30(2):143-158

Hedlund-de Witt A (2012) Exploring worldviews and their relationships to sustainable lifestyles: towards a new conceptual and methodological approach. Ecol Econ 84:74-83. https://doi. org/10.1016/j.ecolecon.2012.09.009

Hedlund-de Witt A, de Boer J, Boersema JJ (2014) Exploring inner and outer worlds: a quantitative study of worldviews, environmental attitudes, and sustainable lifestyles. J Environ Psychol 37:40-54. https://doi.org/10.1016/j.jenvp.2013.11.005

Hitzhusen GE, Tucker ME (2013) The potential of religion for Earth Stewardship. Front Ecol Environ 11:368-376. https://doi. org/10.1890/120322

Hyland ME, Wheeler P, Kamble S, Masters KS (2010) A sense of "special connection", self-transcendent values and a common factor for religious and non-religious spirituality. Arch Psychol Relig 32:293-326. https://doi.org/10.1163/157361210X533265

Ives CD, Kendal D (2014) The role of social values in the management of ecological systems. J Environ Manag 144:67-72. https://doi. org/10.1016/j.jenvman.2014.05.013

Ives CD, Fischer J et al (2017) The self-sabotage of conservation: reply to Manfredo et al. Conserv Biol 31:1483-1485. https://doi. org/10.1111/cobi.13025

Johnston L (2013) Religion and sustainability: social movements and the politics of the environment. Routledge, London 
Jones RP, Cox D, Navarro-Rivera J (2014) Beliefs, sympathizers, \& skeptics: why Americans are conflicted about climate change, environmental policy and science. Public Religion Research Institute, Washington

Kendal D, Raymond CM (2019) Understanding pathways to shifting values over time in the context of social-ecological systems. Sustain Sci

Kenter JO, Associa S, Science M (2014) The deliberative value formation model. Ecosyst Serv. https://doi.org/10.1016/j.ecose r.2016.09.015

Kenter JO, O'Brien L, Hockley N et al (2015) What are shared and social values of ecosystems? Ecol Econ 111:86-99. https://doi. org/10.1016/j.ecolecon.2015.01.006

Kidwell J, Ginn F, Northcott M, Bomberg E, Hague A (2018) Christian climate care: slow change, modesty and eco-theo-citizenship. Geo Geograph Environ. https://doi.org/10.1002/geo2.59

Kitayama S (2002) Culture and basic psychological processestoward a system view of culture : comment on Oyserman et al. (2002). Psychol Bull 128:89-96. https://doi. org/10.1037//0033-2909.128.1.89

Kluckhohn FR, Strodtbeck FL (1961) Variations in value orientations. Row, Peterson, Oxford, England

Koehrsen J (2015) Does religion promote environmental sustainability?-Exploring the role of religion in local energy transitions. Soc Compass 62:296-310. https://doi.org/10.1177/0037768615 587808

Koehrsen J (2017) Religious agency in sustainability transitions: between experimentation, upscaling, and regime support. Environ Innov Soc Transit. https://doi.org/10.1016/j.eist.2017.09.003

Li N, Hilgard J, Scheufele DA, Winneg KM, Jamieson KH (2016) Cross-pressuring conservative Catholics? Effects of Pope Francis' encyclical on the U.S. public opinion on climate change. Clim Chang 139:3-4. https://doi.org/10.1007/s10584-016-1821-z

Manfredo MJ, Teel TL, Gavin MC, Fulton D (2014) Considerations in representing human individuals in social-ecological models. In: Manfredo MJ, Vaske JJ, Rechkemmer A, Duke EA (eds) Understanding society and natural resources: forging new strands of integration across the social sciences. Springer, Dordrecht, pp $67-92$

Manfredo MJ, Bruskotter JT, Teel TL et al (2017) Why social values cannot be changed for the sake of conservation. Conserv Biol 31:772-780. https://doi.org/10.1111/cobi.12855

Martin J-L, Maris V, Simberloff DS (2016) The need to respect nature and its limits challenges society and conservation science. Proc Natl Acad Sci 113:6105-6112. https://doi.org/10.1073/ pnas. 1525003113

Meadows D (1999) Leverage points: places to intervene in a system. The Sustainability Institute, Hartland

Narayanan V (2001) Water, wood, and wisdom: ecological perspectives from Hindu traditions. Daedalus 4:179-206

O'Brien K (2018) Is the $1.5^{\circ} \mathrm{C}$ target possible? Exploring the three spheres of transformation. Curr Opin Environ Sustain 31:153160. https://doi.org/10.1016/j.cosust.2018.04.010

Pew Research Centre (2017) The changing global religious landscape. http://www.pewforum.org/2017/04/05/the-changing-global-relig ious-landscape/. Accessed 12 Feb 2019
Reckwitz A (2002) Toward a theory of social practices: a development in culturalist theorizing. Eur J Soc Theory 5:243-263. https://doi. org/10.1177/13684310222225432

Rolston H (2006) Caring for nature: what science and economics can't teach us but religion can. Environ Values 15:307-313

Saroglou V, Delpierre V, Dernelle R (2004) Values and religiosity: a meta-analysis of studies using Schwartz's model. Personal Individ Differ 37:721-734. https://doi.org/10.1016/j.paid.2003.10.005

Schaefer J, Higgins S (2017) Best practices survey-promising first step toward developing guidelines. Religion and conservation biology Working Group. Society for Conservation Biology

Schultz PW, Zelezny L (2003) Reframing environmental messages to be congruent with American values. Hum Ecol Rev 10:126-136

Schwartz SH (1992) Universals in the content and structure of values: Theoretical advances and empirical tests in 20 countries. In: Zanna M (ed) Advances in experimental social psychology, vol 25. Academic, Orlando, pp 1-65

Schwartz SH (1994) Are there universal aspects in the structure and contents of human values? J Soc Issues 50:19-45

Schwartz SH, Huismans S (1995) Value priorities and religiosity in four western religions. Soc Psychol Q 58:88-107

Shove E (2010) Beyond the ABC: climate change policy and theories of social change. Environ Plan A 42:1273-1285. https://doi. org/10.1068/a42282

Steg L, Vlek C (2009) Encouraging pro-environmental behaviour: an integrative review and research agenda. J Environ Psychol 29:309-317. https://doi.org/10.1016/j.jenvp.2008.10.004

Stern PC (2000) Toward a coherent theory of environmentally significant behavior. J Soc Issues 56:407-424

Tadaki M, Sinner J, Chan KMA (2017) Making sense of environmental values: a typology of concepts. Ecol Soc 22:7

The Alliance of Religions and Conservation (2015) Faith in the future: the Bristol commitments. Bath, UK. http://arcworld.org/downloads/Faith in the Future with cover (UN).pdf. Accessed $12 \mathrm{Feb}$ 2019

The Associated Press-NORC Center for Public Affairs Research (2015) Speaking out on global warming: public attitudes toward the papal encyclical on climate change. http://www.apnorc.org/projects/ Pages/speaking-out-on-global-warming-public-attitudes-towar d-the-papal-encyclical-on-climate-change.aspx. Accessed 12 Feb 2019

Van Riper CJ, Landon AC, Kidd S et al (2017) Incorporating sociocultural phenomena into ecosystem-service valuation: the importance of critical pluralism. Bioscience 67:233-244. https://doi. org/10.1093/biosci/biw170

Van Riper CJ, Winkler-Schor S, Stamberger L, Keller R, Braito M, Raymond CM, Eriksson M, Golebie E, Johnson D (2019) Integrating multi-scale values and pro-environmental behavior in a protected area. Sustain Sci

White MA (2013) Sustainability: i know it when I see it. Ecol Econ 86:213-217. https://doi.org/10.1016/j.ecolecon.2012.12.020

Woodhead L, Partridge C, Kawanami H (2016) Religions in the modern world: traditions and transformations. Routledge, Abingdon

World Council of Churches (1983) Justice, peace and creation. http:// fore.yale.edu/religion/christianity/projects/wcc_jpc/. Accessed 12 Feb 2019 